\title{
Complications of Cement-Augmented Dynamic Hip Screws in Unstable Type Intertrochanteric Fractures - A Case Series Study
}

\author{
Meng-Huang Wu, MD; Po-Cheng Lee ${ }^{1}, \mathrm{MD}$; Kuo-Ti Peng, MD, PhD; Chi-Chuan $\mathrm{Wu}^{1}$, \\ MD; Tsung-Jen Huang, MD; Robert Wen-Wei Hsu, MD
}

Background: Polymethylmethacrylate (PMMA) cement-augmented dynamic hip screws (DHS) have been used as a solution in unstable intertrochanteric fractures (ITF). Our aim was to investigate the complications in PMMA cement-augmented DHS.

Methods: All patients who had received DHS plate osteosynthesis with or without PMMA cement augmentation from August 2005 to July 2009 in one medical center were retrospectively reviewed. The fractures were classified as unstable (31-A2.2, 31-A2.3 and 31-A3) on the basis of the Arbeitsgemeinschaft für Osteosynthesefragen classification. Inclusion criteria were patients older than 75 years, unstable ITF treated with cement-augmented DHS, and a minimum of 12 months of follow-up. Exclusion criteria were stable ITFs, incomplete chart records and imaging studies, loss to follow-up or death before bone union.

Results: Three hundred twenty-one patients received DHS during the study period. Sixty-seven patients were included in the study $(25$ men and 42 women; mean age, 81.2 years). The mean follow-up time was 40.2 months, and the mean union time was 18.5 weeks (12-40 weeks). No patient had a lag screw cut-out. Six patients had delayed union or nonunion with side plate failures, including side plate breakage in 1 patient, screw breakage in 3, screw pullout in 1 , and recurrent side plate breakage and screw breakage in 1 . Deep infection occurred in 1 patient, and 1 had osteonecrosis at the femoral head. The procedure-related complication rate was $8.9 \%$.

Conclusions: Cement-augmented DHS have a different failure mode than screw cutout in conventional DHS. Failures tended to be more related to delayed union, nonunion and resultant side plate construct failure.

(Chang Gung Med J 2012;35:345-53)

Key words: bone cement, complication, dynamic hip screw, intertrochanteric fracture, polymethylmethacrylate

\footnotetext{
From the Department of Orthopedic Surgery, Chang Gung Memorial Hospital at Chiayi; ${ }^{1}$ Department of Orthopedic Surgery, Chang Gung Memorial Hospital at Linkou, Chang Gung University College of Medicine, Taoyuan, Taiwan.

Received: Nov. 30, 2010; Accepted: Jan. 30, 2012

Correspondence to: Dr. Po-Cheng Lee, Department of Orthopedic Surgery, Chang Gung Memorial Hospital at Linkou. 5, Fusing St., Gueishan Township, Taoyuan County 333, Taiwan (R.O.C.) Tel: 886-3-3281200 ext. 2423; Fax: 886-3-3289582;

E-mail: leebone@cgmh.org.tw; reconail@yahoo.com.tw
} 
$\mathrm{O}$ steoporotic intertrochanteric fracture (ITF) is the second leading cause of hospitalization of elderly patients. ${ }^{(1)}$ Successful treatment is challenging, as many factors are related to the patient's final prognosis. Stable fracture fixation is the goal of treatment to improve the quality of life and decrease morbidity in patients with hip fractures, but this in turn depends on the type of fracture and bone quality. ${ }^{(1)}$ In stable ITFs, osteosynthesis using dynamic hip screws (DHS) provides good results, but for unstable ITFs, the best treatment method is still a matter of controversy. Poor bone quality is responsible for common complications, such as failure of fixation, varus collapse and lag screw cut-out, in elderly patients. ${ }^{(2)}$ Kim et al. found that the complication rate when using conventional DHS in unstable ITFs can be as high as $50 \%$ because of screw cut-out. ${ }^{(3)}$ Several methods, such as the Medoff sliding plate, intramedullary nailing, primary endoprosthesis, and bone augmentation using polymethylmethacrylate (PMMA) cement or calcium phosphate cement, have been proposed for unstable ITFs. ${ }^{(4-8)}$ Since 1975 , PMMA cement-augmented DHS have been used as a solution in unstable ITFs by adding an anchoring ability to the lag screw. ${ }^{(9)}$ Some encouraging results have been observed, showing a higher success rate and better functional recovery than with conventional DHS. ${ }^{(10,11)}$ However, complications such as osteonecrosis of the femoral head, nonunion, infection, and screw cut-out can still occur when using PMMA cement augmentation. ${ }^{(7,12)}$ Therefore, our aim was to investigate the complications and failure modes in PMMA cement-augmented DHS. This retrospective study was approved by the institutional review board of our hospital (No 99-1002B).

\section{METHODS}

\section{Subjects}

All patients who had received DHS plate osteosynthesis with or without PMMA cement augmentation from August 2005 to July 2009 in one medical center were reviewed. The fractures were classified as stable (31-A1 and 31-A2.1) or unstable (31-A2.2, 31-A2.3 and 31-A3) on the basis of the Arbeitsgemeinschaft für Osteosynthesefragen/ Orthopaedic Trauma Association classification. ${ }^{(13)}$ The surgeries were performed in the traumatic orthopedic department by 3 trauma orthopedic surgeons.
Inclusion criteria were patients older than 75 years, unstable ITF treated with cement-augmented DHS, and a minimum of 12 months of follow-up. Exclusion criteria were stable ITFs, incomplete chart records and imaging studies, loss to follow-up or death before bone union. A retrospective chart review was performed to collect preoperative, postoperative and intraoperative data, including local and systemic complications. Serial radiographs from the preoperative period and the postoperative period until fracture union was achieved were reviewed.

\section{Surgical techniques}

All surgical operations were performed by 3 senior surgeons with extensive experience in the use of DHS and cement augmentation techniques. The indications for cement-augmented DHS were unstable ITFs, including those with a large posteromedial (PM) fragment, a multifragmentary status, a reverse oblique pattern, and a transtrochanteric pattern in elderly patients with poor lag screw purchase in the femoral head bone. The DHS was inserted using a standard surgical procedure under C-arm fluoroscopic control. The reduction was considered acceptable when the following criteria were met: anatomic or slight valgus alignment on the anteroposterior view, alignment with parallel or slight cervical anteversion on the lateral view, and no more than $1 \mathrm{~cm}$ of displacement between the 2 major fracture fragments. The reduction was maintained by traction and rotation of the injured leg with a boot. The guide wire was inserted in the femoral neck and aimed beneath the center of the femoral head, without penetration into the hip joint. A 135-degree side plate, with at least four holes available below the fracture, was used. Before the side plate was secured to the lateral aspect of the femur, the traction was released to ensure cortical contact between fragments when fracture distraction occurred. Low-viscosity PMMA (Surgical Simplex P, Stryker-Howmedica, Limerick, Ireland) was injected into the screw tract of the proximal fragment when the patient's systemic blood pressure was more than $120 \mathrm{mmHg}$. A dual-speed injection gun (Stryker, Portage, MI, U.S.A.) was used to deliver the cement. The amount of cement retained in the patients was recorded. Because of the nature of proximal femur anteversion, the cement in the proximal fragment had a tendency to flow backward and leak into the fracture gap when the patient 
was lying in the supine position. To overcome the proximal femur anteversion, the fracture table was tilted 30 degrees toward the contralateral side of the injured limb in patients receiving cement augmentation. For maximum cement infiltration, the injection gun was operated in the pressure mode, and a plastic femoral nozzle with an appropriate size of $12 \mathrm{~mm}$ in diameter was inserted as far as possible into the femoral head. The application of a femoral nozzle with a diameter similar to the screw tract has the advantage of completely obliterating the screw tract during cement injection. This can enhance cement intrusion into the surrounding cancellous bone interstices and prevent cement leaking from the screw tract into the fracture site. Cement injection was started from the most proximal part of the screw tract while simultaneously pulling the femoral nozzle backward; the cement injection was stopped when the cement intrusion reached within $1 \mathrm{~cm}$ of the cervicotrochanteric area. The femoral nozzle was then removed, and the assembled hip screw and plate were inserted immediately. Our cement augmentation technique also blocked the screw from sliding within the barrel of the plate because the cement surrounded both the threads and the shaft of the screw. This was intended to prevent the excessive screw sliding commonly encountered in unstable fractures. The filling pattern in our patients showed a diffuse distribution of the cement in the proximal fragment (Fig. 1).

\section{RESULTS}

Three hundred twenty-one patients received DHS plate osteosynthesis with or without PMMA cement augmentation during the study period. Seventy-seven patients received PMMA cement-augmented DHS for closed unstable ITFs. Six patients died ( 4 men and 2 women, Table 1) and 4 patients were lost to follow-up before bone union. Of the remaining 67 patients, 25 were men and 42 were women, and the mean age was 81.2 years (range, 75 94 years). Thirty-eight fractures involved the left side and 29 involved the right. Sixty-three fractures resulted from falls, 2 from high-energy mechanisms (motor-vehicle accidents), and 2 were revision surgeries after conventional DHS. According to the American Society of Anesthesiologists physical status classification (www.asahq.org/clinical/physical-

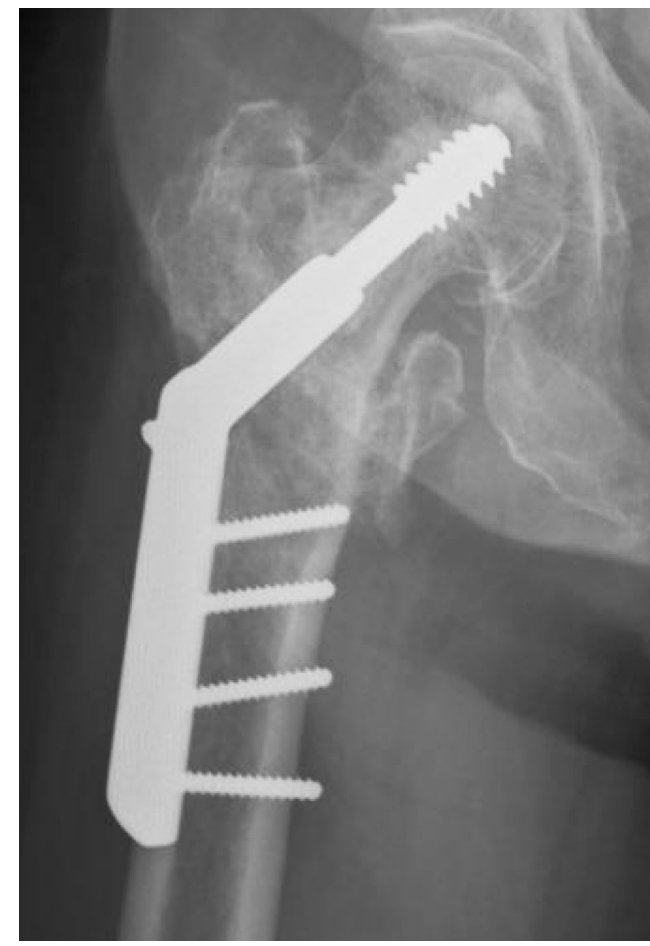

Fig. 1 Diffuse cement distribution pattern in cement augmented dynamic hip screw surgery.

status.htm), 2 were class I, 32 were class II, 29 were class III, and 4 were class IV. Four patients were completely non-ambulatory preoperatively. The average length of hospitalization was 9.47 days (range, 422 days). The mean operation time was 71.2 minutes (range, 62-93 minutes). The mean fluoroscopy time was 82.3 seconds (range, $60-130$ seconds). The mean operative blood loss was $260 \mathrm{~mL}$ (range, 80-450 $\mathrm{mL}$ ). All patients had an acceptable reduction of the fracture and a desired position for the lag screw. Postoperatively, the mean follow-up time was 40.2 months (range, 12-56 months). Except for 1 patient requiring a total hip replacement because of deep infection, and 6 patients who had revision surgeries, the mean union time for the remaining 60 patients was 18.5 weeks (12-40 weeks). Eventual fracture union was achieved in 66 patients by 52 weeks.

Eight patients had complications (Table 2); none had a lag screw cut-out. Six patients had implant failure that required further intervention to achieve fracture union. The most common failure mode was delayed union or nonunion with side plate failure, which included side plate breakage in 1 patient (Fig. 
Table 1. Mortalities and Morbidities

\begin{tabular}{lclclll}
\hline Age & Sex & Co-morbidities & ASA & Time interval & Events & Final status \\
\hline 87 & F & HTN, Peptic ulcer disease & 3 & 2 months & Ileus, hyponatremia & Discharged \\
84 & F & DM, HTN, CVA & 3 & 3 months & Neurogenic bladder, angina & Discharged \\
75 & F & DM, HTN, Adrenal insufficiency & 2 & 10 months & L1 compression fracture & $\begin{array}{l}\text { Vertebroplasty and } \\
\text { discharged }\end{array}$ \\
& & & & & & Discharged \\
85 & F & Nil & 3 & 3 days & UGI bleeding & Expired \\
79 & F & Bedridden, liver cirrhosis & 3 & 14 months & Pneumonia & Expired \\
85 & M & HTN, HCV & 2 & 5 days & Acute cardiac arrest & Expired \\
88 & M & Multiple myeloma, bilateral & 3 & 6 months & Incarcerated hernia with sepsis & Expired \\
79 & M & HTN, CHF, COPD, old TB & 3 & 13 months & TB pneumonia & Expired \\
78 & F & ESRD & 3 & 5 months & Peritonitis & Expired \\
\hline
\end{tabular}

Abbreviations: HTN: hypertension; DM: diabetes mellitus; HCV: hepatitis C virus carrier; CVA: cerebrovascular accident; COPD: chronic obstructive pulmonary disease; CHF: congestive heart failure; TB: tuberculosis; ESRD: end-stage renal disease; HCC: hepatocellular carcinoma; UGI: upper gastrointestinal tract; *: 77 patients received cement augmented dynamic hip screws.

Table 2. Complications of Cement Augmented Dynamic Hip Screws*

\begin{tabular}{|c|c|c|c|c|c|c|c|}
\hline Age & Sex & Diagnosis & Co-morbidities & Time to failure (m) & Complications & Operation & Time to union $(\mathrm{m})$ \\
\hline 68 & $\mathrm{~F}$ & Left ITF & DM, HTN & 5 & Screw breakage & $\begin{array}{l}\text { Side plate exchange } \\
\text { and bone graft }\end{array}$ & 6 \\
\hline 75 & $\mathrm{~F}$ & Left ITF & $\begin{array}{l}\text { DM, HTN, HBV, } \\
\text { adrenal insufficiency }\end{array}$ & 22 & Screw breakage & Side plate exchange & 8 \\
\hline 78 & $\mathrm{~F}$ & Left ITF s/p DHS & HTN, COPD & 5 & Screw breakage & Side plate exchange & 7 \\
\hline 68 & $\mathrm{~F}$ & Left ITF & HTN & 12 & Side plate breakage & $\begin{array}{l}\text { Side plate exchange } \\
\text { and bone graft }\end{array}$ & 6 \\
\hline 47 & M & Left ITF & Smoking & 3 & $\begin{array}{l}\text { Recurrent plate } \\
\text { breakage }\end{array}$ & $\begin{array}{l}\text { Side plate exchange } \\
\text { and bone graft }\end{array}$ & 6 \\
\hline 87 & $\mathrm{~F}$ & Left ITF & CRI, HTN, psoriasis & 3 & Plate pullout & $\begin{array}{l}\text { Side plate exchange } \\
\text { and bone graft }\end{array}$ & 5 \\
\hline 56 & M & Right ITF & HTN, CVA & 3 & Osteonecrosis & - & - \\
\hline 66 & M & Right ITF & Gout, asthma, HTN & 6 & Infection & $\begin{array}{l}\text { Debridement and } 2 \\
\text { stage THR }\end{array}$ & - \\
\hline
\end{tabular}

Abbreviations: ITF: intertrochanteric fracture, s/p: status post; DHS: dynamic hip screw; DM: diabetes mellitus; HTN: hypertension; HBV: hepatitis B virus carrier; COPD: chronic obstructive pulmonary disease; CRI: chronic renal insufficiency; CVA: cerebrovascular accident; THR: total hip replacement; *: 67 patients included in this study.

2), screw breakage in 3 patients (Fig. 3), screw pullout in 1 patient (Fig. 4), and recurrent side plate breakage and screw breakage in 1 patient. All these patients had a good post-op ambulatory status and all denied any traumatic event before implant failure.
They all had side plate revision and 4 patients had allogenic bone grafting in the bone gap. Final bone unions were achieved in all patients. Deep infection occurred in 1 patient, who required surgical debridement and a total hip replacement. One patient had 


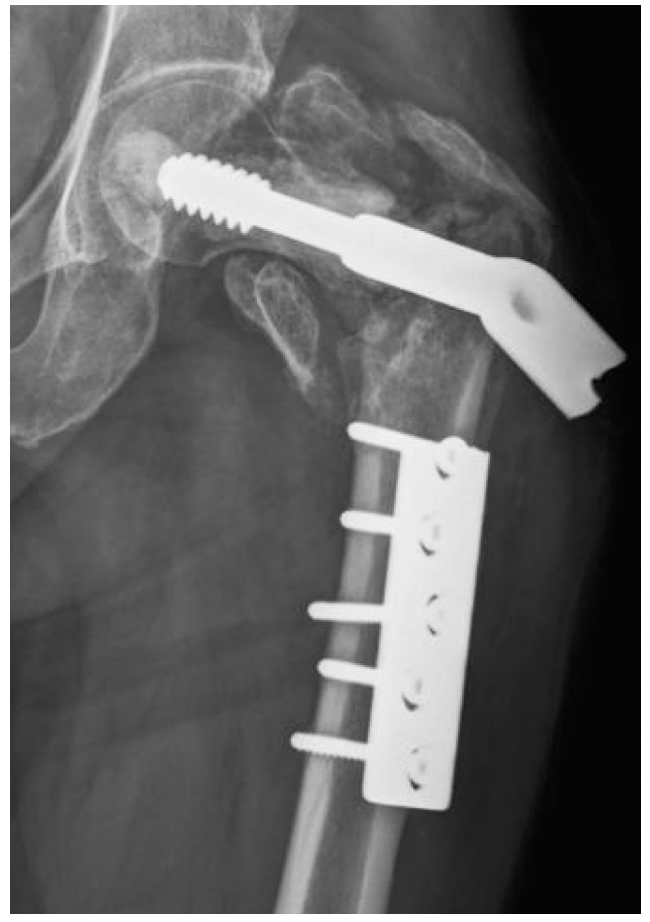

Fig. 2 Side plate breakage from the screw hole.

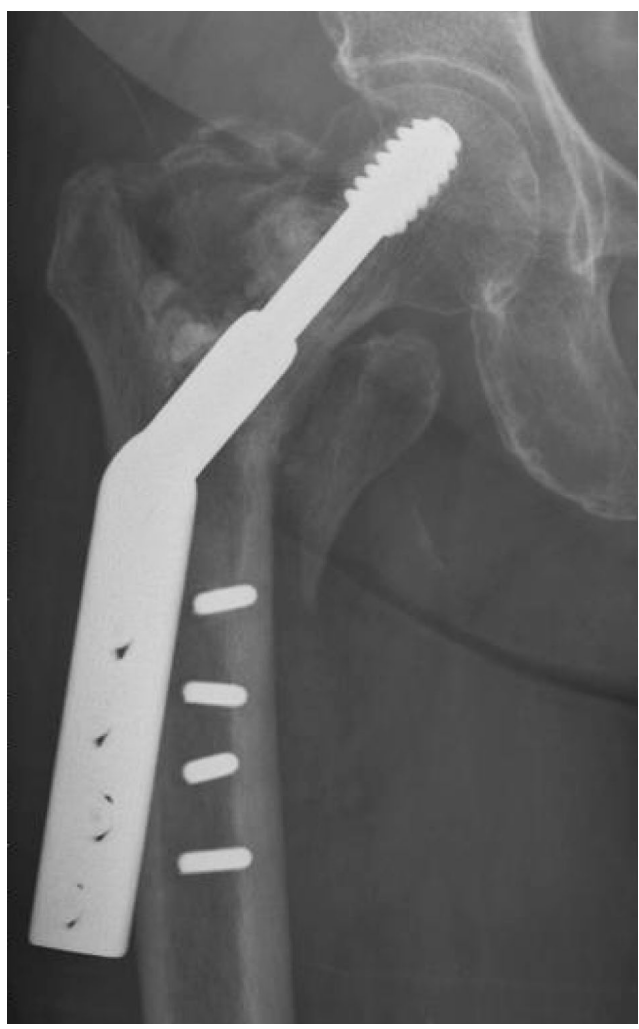

Fig. 3 Side plate screw breakage.

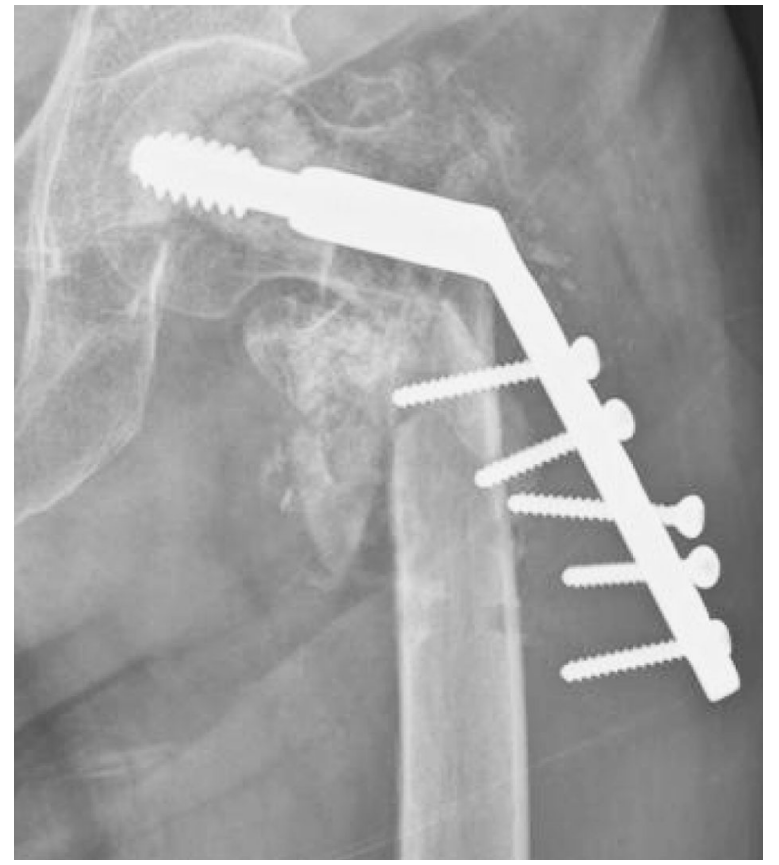

Fig. 4 Side plate screw pullout.

osteonecrosis at the femoral head without clinical symptoms. Four patients had co-morbidities during hospitalization, but all were discharged after treatment (Table 2). Six patients died of causes such as pneumonia, septic hip, acute cardiac arrest, incarcerated hernia, and peritonitis, but none of these causes of death were directly related to cement use. The procedure-related complication rate was $8.9 \%$.

\section{DISCUSSION}

Conventional DHS for stable type ITFs have demonstrated good results; however, the complication rate of conventional DHS can be as high as 50\% in patients with osteoporosis and unstable fractures. ${ }^{(3)}$ Screw cut-out is the most common complication; Bonnaire et al. found that screw cut-outs were strongly connected to the bone density of the trabecular bone in the femoral head in conventional DHS. ${ }^{(14)}$ In our series, poor trabecular bone quality in the femoral head did not lead to screw cut-out if cement augmentation was adequate to strengthen the osteoporotic bone. Failures were more related to delayed union or nonunion with side plate failure, including side plate screw pullout, screw breakage, and plate breakage, which are rarely reported..$^{(15-17)}$ 
Because of the high complication rate, the use of DHS in unstable ITFs has become less favored. The use of intramedullary devices provides more effective control over screw sliding by acting as a lateral buttress, resulting in a tendency to less frequent cut-out. ${ }^{(16)}$ On the other hand, iatrogenic femoral fractures are a persistent risk when using intramedullary devices. ${ }^{(18)}$ Anglen et al. observed a dramatic increase from $3 \%$ to $67 \%$ in the use of intramedullary devices in ITF in recent decades. ${ }^{(19)}$ With more frequent use and technique-related errors, patients managed with intramedullary nailing have had more procedure-related complications, particularly bone fracture. ${ }^{(19)}$ Recent reports have shown no significant differences in the final functional outcome between DHS and intramedullary devices. ${ }^{(20,21)}$ Furthermore, intramedullary devices for unstable ITFs have the disadvantages of difficult reduction, intraoperative complications as a result of the bulky proximal part, persistent thigh pain due to stress concentration around the nail tip, implant failure due to varus angulation, and risk of femoral shaft fracture. ${ }^{(1,18)}$

PMMA cement augmentation for DHS is an effective way to prevent screw cut-out in osteoporotic ITF treatment. ${ }^{(10)}$ Diffuse distribution of low viscosity cement has provided better load to cut-out in several reports. ${ }^{(10,22,23)}$ Choueka et al. performed a cadaver study and found the greatest average load to failure was increased in the cemented sliding hip screw $(4.0 \times 103 \mathrm{~N})$, and the lowest was in the uncemented sliding hip screw $(3.6 \times 103 \mathrm{~N}) .{ }^{(23)}$ Another cadaver study by Augat et al. found significantly better initial stability with the cement-augmented sliding hip screws in unstable ITFs. ${ }^{(22)}$ Clinical reports show encouraging results for cement augmentation. In a report of 53 unstable ITFs from Bartucci et al., 1 failure (in 21 fractures) in the cement-augmented group and 10 failures (in 17 fractures) in the noncement-augmented group were due to failure of fixation $(p<0.01){ }^{(14)}$ In a prospective comparison study of conventional DHS and cement-augmented DHS in unstable ITFs by Lee et al., screw sliding, femoral shortening, and varus collapse of the proximal fragment were all significantly reduced in the cementaugmented group at the 1-year follow-up ( $p<0.001$, $p<0.001, p<0.001$, respectively), and the mean hip pain score was significantly lower in the cement-augmented DHS group $(p<0.008){ }^{(11)}$
In our series, the procedure-related complication rate was $8.9 \%$, without screw cut-out from the femoral head. This was because of better fixation of the lag screw inside the femoral head and blockage of barrel sliding by the cement to maintain fracture reduction and prevent screw cut-out and malunion in conventional DHS. ${ }^{(24)}$ This construct is similar to a fixed-angle device and therefore can be used in unstable fractures, decreasing the rate of femoral shortening-related complications of conventional DHS. ${ }^{(11)}$ However, complications were still noted with this method. Cheng et al. reported that 6 of 38 patients with cement-augmented sliding hip screws had late complications such non-union at the trochanteric fracture, protruding pin, partial destruction of the femoral head, subcapital fracture of the femoral neck, and avascular necrosis of the femoral head 1 year after surgery. These were related to inappropriate placement and an excessive amount of cement, together with inadequate new bone formation. ${ }^{(12)}$ Side plate failure is very rare with conventional sliding hip screws, and only 4 cases, which were related to femoral shortening and varus malalignment, have been reported. ${ }^{(17,25)}$ A similar metal failure was also reported with intramedullary nails when there was a short nail length in the gamma nail, loss of PM support or overdistraction without bone-to-bone contact, and varus angulation during fixation. ${ }^{(26)}$ Similar factors may produce a varus deforming force, causing implant failure from the side plate screw hole, screw-plate junction with screw breakage, or screw-bone interface with screw pullout when the side plate has an inadequate length and fixation. ${ }^{(16)}$

The construct of cement-augmented DHS is different from that of conventional DHS because the fixed lag screw without a telescoping effect will have a greater load transfer from the implant. Apel et al. found that the PM fragment is the keystone to decrease varus moment and provide stability in ITFs. ${ }^{(27)}$ In the presence of a large PM fragment in unstable ITFs, anatomic reduction and fixation of the PM fragment allowed the femur to resist an average maximum load which was $57 \%$ greater than identical fractures with the fragment excluded. Fixation of a small PM fragment increased construct strength by an average of $17 \%$ over no fixation. ${ }^{(27)}$ In unstable ITFs, the PM fragment may be too comminuted to be fixed and additional bone grafting with iliac bone, 
allogenic bone, or a bone substitute should be strongly considered to provide PM support and prevent construct failure. Besides lack of PM support, the length of the side plate may have been another reason for the implant failures in our series. Verhofstad et al suggested that a 2-hole side plate is sufficient in stable ITFs. ${ }^{(28)}$ However, in patients with severe osteoporosis with unstable ITFs, side plate pullout still can be observed, even in low energy trauma with a standard side plate with 4 screw holes. ${ }^{(15)}$ Side plates with 4 screw holes were used in 3 patients with screw breakage, and a side plate with 5 screw holes was used in another case. Facing greater putout force than with stable fractures, a longer side plate (more than 4 screw holes) may be required to ensure the amount of effectively-purchased cortex, provide a more divided stress distribution to the longer plate on more screws and provide a longer lever arm to resist the varus moment. Unlike screw pullout and screw breakage, side plate breakage from the junction of the lag screw is related to a lack of PM support, but not inadequate side plate fixation. The revision surgery should include side plate exchange and PM bone grafting. If PM support cannot be ensured, a Dimond-Hughston medial displacement osteotomy is recommended to correct alignment and provide PM stability. ${ }^{(29)}$ Protective weight-bearing should be used until a bone healing sign is noted on radiography, because implant failure occurred as late as 12 months after surgery with minor trauma in our series. Cheng et al. also reported that most patients had late complications because of impaired healing ability in osteoporotic bone. ${ }^{(12,30)}$

One case of avascular necrosis of the femoral head was noted but the patient had no clinical symptoms. Concerns about thermal necrosis when using PMMA cement have been proposed in several studies. Heini et al. injected approximately $36 \mathrm{ml}$ of bone cement into the femoral head and femoral neck with a resultant mean temperature increase of $22.1^{\circ} \mathrm{C}$ at the femoral neck. ${ }^{(31)}$ A temperature rise of this magnitude is cause for concern with regard to thermal damage to blood vessels and femoral head necrosis. Stoffel et al. found the mean increase in temperature at the femoral neck was $3.7^{\circ} \mathrm{C}$ in augmented bones, using a modified method. ${ }^{(7)}$ Boner et al. found the highest temperatures were measured inside the PMMA, with a significant drop in average maximum temperatures from the center of the PMMA to the
PMMA/bone interface. ${ }^{(32)}$ There is a risk of thermal necrosis with PMMA layer thicknesses greater than $5.0 \mathrm{~mm}$. No risk of thermal necrosis at the PMMA/bone interface or in the surrounding bone was found when using up to $6.0 \mathrm{cc}$ of PMMA. Clinical reports of PMMA cement augmentation showed a low incidence of osteonecrosis; Cheng et al. reported only 1 case of osteonecrosis among 38 patients that received a Dimon-Hughston displacement osteotomy and cement augmentation. ${ }^{(12)}$ Therefore, the risk of osteonecrosis seems to be low when using PMMA cement augmentation in this modified technique.

\section{Limitations}

This retrospective study cannot provide detailed information and some patients may have been lost to follow-up. The follow-up rate was $87 \%$ and all had complete records which provided most of the information needed to reduce these limitations. To date, no biomechanical study has been able to determine the adequate length of the side plate in cement-augmented DHS. However, this series can provide information to prevent complications when using this technique in patients with severe osteoporosis.

\section{Conclusions}

Cement-augmented DHS have a different failure mode from screw cutout in conventional DHS. The failed cases were more related to delayed union, nonunion and resultant side plate construct failure.

\section{REFERENCES}

1. Lorich DG, Geller DS, Nielson JH. Osteoporotic pertrochanteric hip fractures: management and current controversies. Instr Course Lect 2004;53:441-54.

2. Simpson AH, Varty K, Dodd CA. Sliding hip screws: modes of failure. Injury 1989;20:227-31.

3. Kim WY, Han CH, Park JI, Kim JY. Failure of intertrochanteric fracture fixation with a dynamic hip screw in relation to pre-operative fracture stability and osteoporosis. Int Orthop 2001;25:360-2.

4. Olsson O, Ceder L, Hauggaard A. Femoral shortening in intertrochanteric fractures. A comparison between the Medoff sliding plate and the compression hip screw. J Bone Joint Surg Br 2001;83:572-8.

5. Ruecker AH, Rupprecht M, Gruber M, Gebauer M, Barvencik E, Briem D, Rueger JM. The treatment of intertrochanteric fractures: results using an intramedullary 
nail With integrated cephalocervical screws and linear compression. J Orthop Trauma 2009;23:22-30.

6. Haentjens P, Lamraski G. Endoprosthetic replacement of unstable, comminuted intertrochanteric fracture of the femur in the elderly, osteoporotic patient: a review. Disabil Rehabil 2005;27:1167-80.

7. Stoffel KK, Leys T, Damen N, Nicholls RL, Kuster MS. A new technique for cement augmentation of the sliding hip screw in proximal femur fractures. Clin Biomech (Bristol, Avon) 2008;23:45-51.

8. Collinge C, Merk B, Lautenschlager EP. Mechanical evaluation of fracture fixation augmented with tricalcium phosphate bone cement in a porous osteoporotic cancellous bone model. J Orthop Trauma 2007;21:124-8.

9. Harrington KD. The use of methylmethacrylate as an adjunct in the internal fixation of unstable comminuted intertrochanteric fractures in osteoporotic patients. J Bone Joint Surg Am 1975;57:744-50.

10. Szpalski M, Descamps PY, Hayez JP, Raad E, Gunzburg R, Keller TS, Kosmopoulos V. Prevention of hip lag screw cut-out by cement augmentation: description of a new technique and preliminary clinical results. J Orthop Trauma 2004; 18:34-40.

11. Lee PC, Hsieh PH, Chou YC, Wu CC, Chen WJ. Dynamic hip screws for unstable intertrochanteric fractures in elderly patients--encouraging results with a cement augmentation technique. J Trauma 2010;68:95464.

12. Cheng CL, Chow SP, Pun WK, Leong JC. Long-term results and complications of cement augmentation in the treatment of unstable trochanteric fractures. Injury 1989;20:134-8.

13. Fracture and dislocation compendium. Orthopaedic Trauma Association Committee for Coding and Classification. J Orthop Trauma 1996;10 Suppl 1:v-ix, 1154.

14. Bonnaire F, Weber A, Bosl O, Eckhardt C, Schwieger K, Linke B. "Cutting out" in pertrochanteric fractures--problem of osteoporosis. Unfallchirurg 2007;110:425-32.

15. Seijas R, Orduna JM, Castro MC, Baliarda J, Granados N, Alcantara E. Unusual case of osteosynthesis failure in a hip fracture: side-plate pull-out. Hip Int 2009;19:402-4.

16. Haidukewych GJ. Intertrochanteric fractures: ten tips to improve results. J Bone Joint Surg Am 2009;91:712-9.

17. Khanna A, Parker M. Rare mode of dynamic hip screw failure. Hip Int 2008;18:239-41.

18. Audige L, Hanson B, Swiontkowski MF. Implant-related complications in the treatment of unstable intertrochanteric fractures: meta-analysis of dynamic screwplate versus dynamic screw-intramedullary nail devices. Int Orthop 2003;27:197-203.

19. Anglen JO, Weinstein JN; American Board of Orthopaedic Surgery Research Committee. Nail or plate fixation of intertrochanteric hip fractures: changing pat- tern of practice. A review of the American Board of Orthopaedic Surgery Database. J Bone Joint Surg Am 2008;90:700-7.

20. Adams CI, Robinson CM, Court-Brown CM, McQueen MM. Prospective randomized controlled trial of an intramedullary nail versus dynamic screw and plate for intertrochanteric fractures of the femur. J Orthop Trauma 2001;15:394-400.

21. Harrington P, Nihal A, Singhania AK, Howell FR. Intramedullary hip screw versus sliding hip screw for unstable intertrochanteric femoral fractures in the elderly. Injury 2002;33:23-8.

22. Augat P, Rapp S, Claes L. A modified hip screw incorporating injected cement for the fixation of osteoporotic trochanteric fractures. J Orthop Trauma 2002;16:311-6.

23. Choueka J, Koval KJ, Kummer FJ, Zukerman JD. Cement augmentation of intertrochanteric fracture fixation: a cadaver comparison of 2 techniques. Acta Orthop Scand 1996;67:153-7.

24. Beckmann J, Ferguson SJ, Gebauer M, Luering C, Gasser B, Heini P. Femoroplasty--augmentation of the proximal femur with a composite bone cement--feasibility, biomechanical properties and osteosynthesis potential. Med Eng Phys 2007;29:755-64.

25. Spivak JM, Zuckerman JD, Kummer FJ, Frankel VH. Fatigue failure of the sliding screw in hip fracture fixation: a report of three cases. J Orthop Trauma 1991;5:32531.

26. Park SY, Yang KH, Yoo JH, Yoon HK, Park HW. The treatment of reverse obliquity intertrochanteric fractures With the intramedullary hip nail. J Trauma Inj Infect Crit Care 2008;65:852-7.

27. Apel DM, Patwardhan A, Pinzur MS, Dobozi WR. Axial loading studies of unstable intertrochanteric fractures of the femur. Clin Orthop Relat Res 1989:156-64.

28. Verhofstad MH, van der Werken C. DHS osteosynthesis for stable pertrochanteric femur fractures with a two-hole side plate. Injury 2004;35:999-1002.

29. Brackett B. Dimon-Hughston osteotomy. Am J Orthop (Belle Mead NJ) 1999;28:266.

30. Giannoudis P, Tzioupis C, Almalki T, Buckley R. Fracture healing in osteoporotic fractures: is it really different? A basic science perspective. Injury 2007;38 Suppl 1:S90-9.

31. Heini PF, Franz T, Fankhauser C, Gasser B, Ganz R. Femoroplasty-augmentation of mechanical properties in the osteoporotic proximal femur: a biomechanical investigation of PMMA reinforcement in cadaver bones. Clin Biomech (Bristol, Avon) 2004;19:506-12.

32. Boner V, Kuhn P, Mendel T, Gisep A. Temperature evaluation during PMMA screw augmentation in osteoporotic bone--an in vitro study about the risk of thermal necrosis in human femoral heads. J Biomed Mater Res B Appl Biomater 2009;90:842-8. 


\title{
使用骨水泥動態骼部骨釘治療不榉定性轉子間骨折之併發症- 案例系列研究
}

\author{
吴孟晃 李柏成 ${ }^{1}$ 彭國狄 吳基銓 ${ }^{1}$ 黄聰仁 許文蔚
}

背 景：使用骨水泥動態髖部骨釬可以治療不稳定之轉子間骨折, 但臨床上仍有可能發生併 發症。本研究目的是希望了解骨水泥動態髂部骨釘之併發症。

方 法: 回溯分析在 2005 八月至 2009 七月間於單一醫學中心中接受動態髖部骨釘治療轉子 間骨折之病人。收案條件包括 Arbeitsgemeinschaft für Osteosynthesefragen classification 分類中的不穞定骨折 (31-A2.2, 31-A2.3, 31-A3) 使用骨水泥動態髖部骨釷，年紀 大於 75 歲, 追蹤大於 12 個月。排除條件包括稳定骨折, 不完整的病歷記載與影 像, 於骨癒合前失去追蹤或死亡。

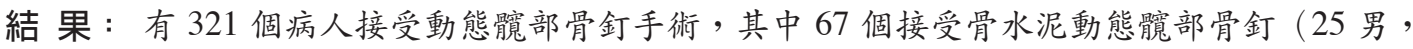
42 女)，平均年齡 81.2 歲。追蹤時間平均 40.2 月。平均癒合時間 18.5 周（12 至 40 周)。沒有病人有骨釷穿出, 6 個病人有延遲癒合或未癒合引起側鋼板失敗包括 1 個 側鋼板斷裂，3 個骨釘斷裂，1 個骨釷鬆脱，及 1 個反覆側鋼板斷裂。深部感染 1 位, 缺血性股骨頭壤死有 1 名病人。

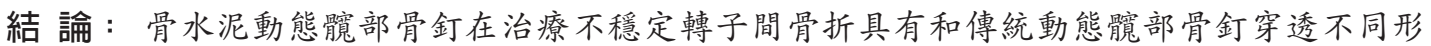
式的併發症。其併發症大多跟延痋癒合或未癒合引起倒鋼板失敗有關。

(長庚醫誌 2012;35:345-53)

關鍵詞：骨水泥，併發症，動態髖部骨釷，轉子間骨折，polymethylmethacrylate

長庚醫療財團法人嘉義長庚紀念醫院 骨科系 ; 1長庚醫療財團法人林口長庚紀念醫院 骨科 ; 長庚大學 醫學院 受文日期：民國99年11月30日；接受刊載：民國101年1月30日

通訊作者: 李柏成醫師, 長庚醫療財團法人林口長庚紀念醫院 骨科。桃園縣333龜山鄉文化一路259號。

Tel: (03)3281200轉2423; Fax: (03)3289582; E-mail: leebone@cgmh.org.tw; reconail@yahoo.com.tw 